\title{
Antibacterial Screening of Fifteen Cameroonian
}

\section{Medicinal Plants against Staphylococcus aureus,}

\section{Escherichia coli, Pseudomonas aeruginosa and}

\section{Salmonella typhi}

\author{
Elisabeth Zeuko'o Menkem, Rufin Marie Toghueo Kouipou, Cedric Derick Jiatsa Mbouna, Maguerite Simo \\ Kamdem, Patrick Valere Tsouh Fokou and Fekam Boyom Fabrice \\ Antimicrobial Agents Unit, Laboratory for Phytobiochemistry and Medicinal Plants Studies, Department of Biochemistry, University \\ of Yaoundé 1, Yaoundé P.O. Box 812, Cameroon
}

\begin{abstract}
Multi-drug resistant microbial infections caused by Staphylococcus aureus, Escherichia coli, Pseudomonas aeruginosa and Salmonella typhi represent a critical public health issue worldwide. Plant-derived agents are credible sources for search and development of alternative antimicrobials to fight these infections. This study describes the in-vitro antibacterial activity of plants extracts from 15 medicinal plants of the Cameroonian pharmacopeia against Escherichia coli, Staphylococcus aureus, Pseudomonas aeruginosa and Salmonella typhi. Plants selected based on their ethnopharmacological uses were extracted by either maceration or decoction using distilled water, ethanol, methanol and ethylacetate. The afforded extracts were phytochemically screened for bioactive secondary metabolites. The microdilution method was used to assess the antibacterial activity. The two promising extracts were tested in combination using the checkboard technique. Eighty one extracts showed antibacterial activity with eight having minimum inhibitory concentrations below $2.5 \mathrm{mg} / \mathrm{mL}$. Results from combination assays with extracts from Terminalia catappa and Gnidia glauca leaves showed synergistic effect against Escherichia coli, Pseudomonas aeruginosa and Salmonella typhi and additive effect against Staphylococcus aureus. These extracts mainly contained saponins, tannins, glucosides, phenols, triterpenes and anthraquinones. These results support the ethnobotanical claims and indicate further directions for the investigation of plants extracts to develop alternative drugs against multi-resistant bacteria.
\end{abstract}

Key words: Antibacterial activity, Terminalia catappa, Gnidia glauca, combination, phytochemical screening.

\section{Introduction}

Multi-drug resistant microbial infections caused by Gram-positive bacteria (such as Staphylococcus aureus) and Gram-negative (such as Escherichia coli, Pseudomonas aeruginosa and Salmonella typhi) represent an exponentially growing health problem affecting communities worldwide [1-3]. In recent years, they emerged as an important nosocomial pathogen due to multiple drug resistant mechanisms [4]. They cause a variety of infections that include pneumonia, wound, urinary tract, bloodstream and intra-abdominal

Corresponding author: Elisabeth Zeuko'o Menkem, Ph.D., research fields: antimicrobial agents research, drug discovery. infections [5]. The Gram-positive Staphylococcus aureus, when pathogenic, is a common cause of skin infections (e.g., boils), respiratory disease (e.g., sinusitis) and food poisoning. Disease-associated strains often promote infections by producing potent protein toxins and expressing cell-surface proteins that bind and inactivate antibodies. The emergence of antibiotic-resistant forms of pathogenic Staphylococcus aureus (e.g., MRSA (methicillin-resistant Staphylococcus aureus)) is a worldwide problem in clinical medicine. The following Gram-negative bacteria also exact a heavy toll. Virulent strains of Escherichia coli can cause gastroenteritis, urinary tract infections and neonatal 

Escherichia coli, Pseudomonas aeruginosa and Salmonella typhi

meningitis. In Cameroon, these infections are increasing with children being the most affected. In rarer cases, virulent strains are also responsible for hemolytic-uremic syndrome, peritonitis, mastitis, septicemia and Gram-negative pneumonia. Pseudomonas aeruginosa is a common bacterium that can cause disease in animals, including humans. It is found in soil, water, skin flora and most man-made environments throughout the world. As an opportunistic, nosocomial pathogen of immunocompromised individuals, Pseudomonas aeruginosa typically infects the pulmonary tract, urinary tract, burns, wounds and also causes other blood infections. Salmonella bacteria are zoonotic and can be transferred between humans and other animals. Many infections are due to ingestion of contaminated food. Salmonella, such as Salmonella enterica subsp. enterica serovar typhi, can cause serious illness. Salmonella typhi is adapted to humans and does not occur in other animals [6-9]. The used synthetic antibiotics are costly and are out of range from the patient belonging to developing countries, the microorganism develop resistance against antibiotics and the antibiotics may be associated with adverse effects on the host, including hypersensitivity, immune suppression and also allergic reactions. Due to the side effects and the resistance built by pathogens against antibiotics, much attention has been paid to extract and bioactive compounds from plants used in herbal medicine $[5,10]$. Cameroon has a rich biodiversity and established tradition in the use of herbal medicine for the treatment of various diseases [11]. The screening of plant extracts and phytochemicals for antimicrobial activity has shown that higher plants, especially their secondary metabolites, are a source of structurally diverse bioactive compounds with a wide range of pharmacological activities [12, 13].

In a search for alternative medicines against bacterial infections, this study was designed to investigate the in-vitro antibacterial activity of extracts from 15 medicinal plants of the Cameroonian pharmacopeia and their combination against Escherichia coli, Staphylococcus aureus, Pseudomonas aeruginosa and Salmonella typhi.

\section{Material and Methods}

\subsection{Collection and Extraction of Plant Materials}

Plant materials were harvested and identified as Azadirachta indica, Monodora tenuifolia, Terminalia catappa, Polyalthia suaveolens, Gnidia glauca, Uvaria muricata, Uvaria angolensis, Uvariodendron callophylum, Monodora miristica, Hypericum lanceolatum, Piptostigma calophyllum, Sizygium aromaticum, Xantozylum xanthozoloides, Gnidia glauca and Viscum album at the National Herbarium of Cameroon, Yaoundé, where voucher specimens were deposited under specific reference numbers. Plants reference numbers, traditional uses, place of collection and previous studies are summarized in Table 1.

$100 \mathrm{~g}$ of ground plant material from each dried powder of Azadirachta indica, Monodora tenuifolia, Terminalia catappa, Viscum album, Gnidia glauca, Uvaria muricata, Uvaria angolensis, Uvariodendron calophyllum, Monodora miristica, Hypericum lanceolatum, Polyalthia suaveolens and Piptostigma calophyllum were macerated in $1 \mathrm{~L}$ capacity glass bottle using distilled water, $95 \%$ ethanol, $70 \%$ ethanol and methanol. Sizygium aromaticum, Xantozylum xanthozoloides and Gnidia glauca were extracted by decoction. Viscum album was also macerated in ethyl acetate. The samples were periodically stirred in the mornings and evenings per day using a mechanical shaker. The extracts were filtered using filter paper (Whatman paper No. 1), and concentrated under vacuum using a rotary evaporator (Rotavapor BUCHI 071). Water extract were dried under ventilation. The extracts obtained were stored at $4{ }^{\circ} \mathrm{C}$ in the refrigerator until bioassay.

\subsection{Phytochemical Screening}

The extracts with promising activity were subjected to phytochemical screening to detect the presence of 


\begin{tabular}{|c|c|c|c|c|c|}
\hline 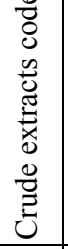 & 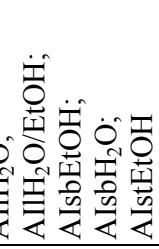 & 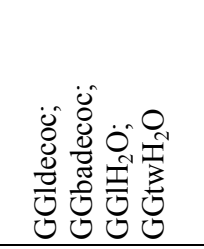 & 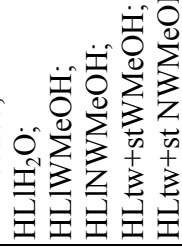 & $\sum_{\Sigma}^{2}$ & 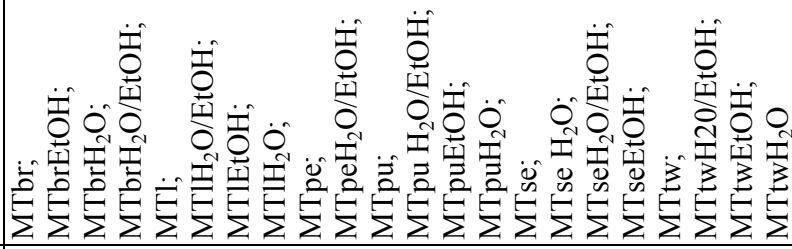 \\
\hline 噌 & 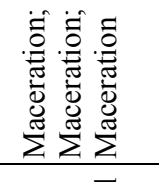 & 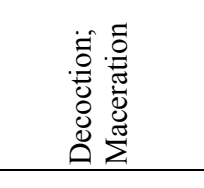 & 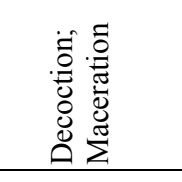 & 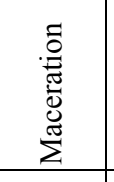 & 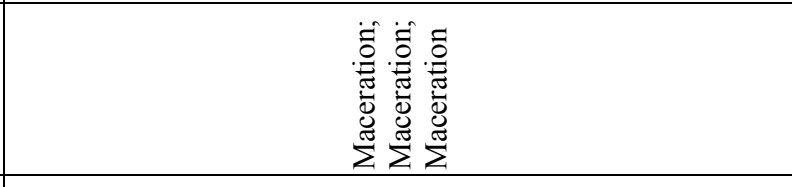 \\
\hline 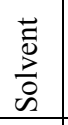 & 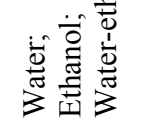 & 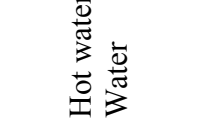 & 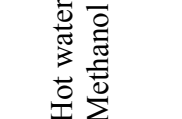 & 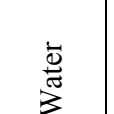 & \\
\hline 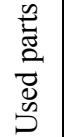 & 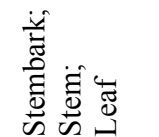 & 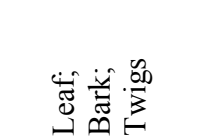 & 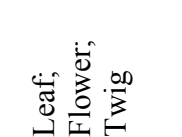 & 总 & 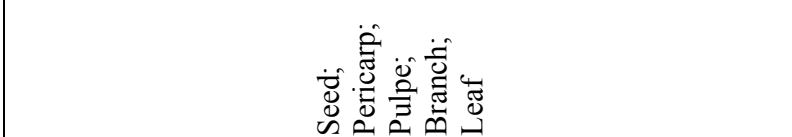 \\
\hline 童 & 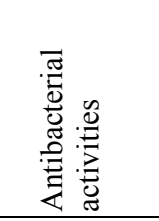 & 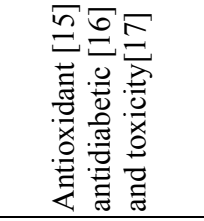 & 爱可 & 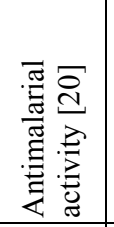 & 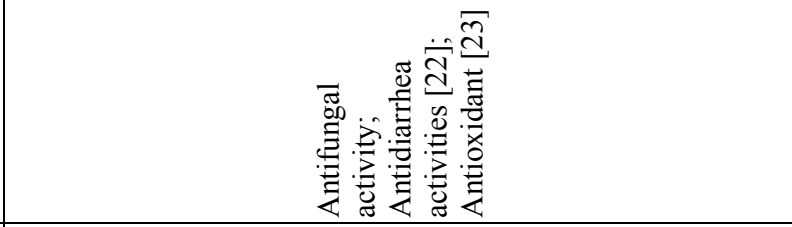 \\
\hline & 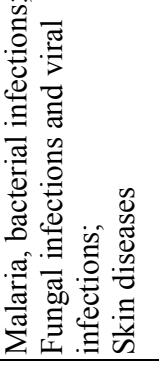 & 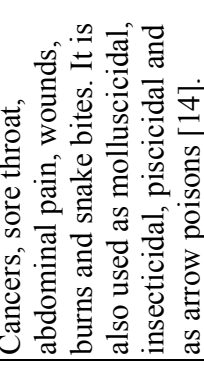 & 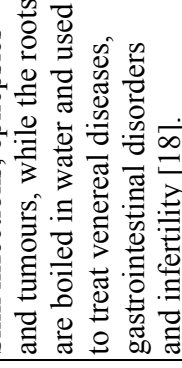 & 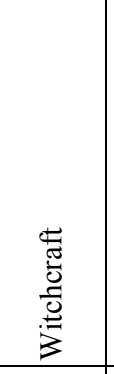 & 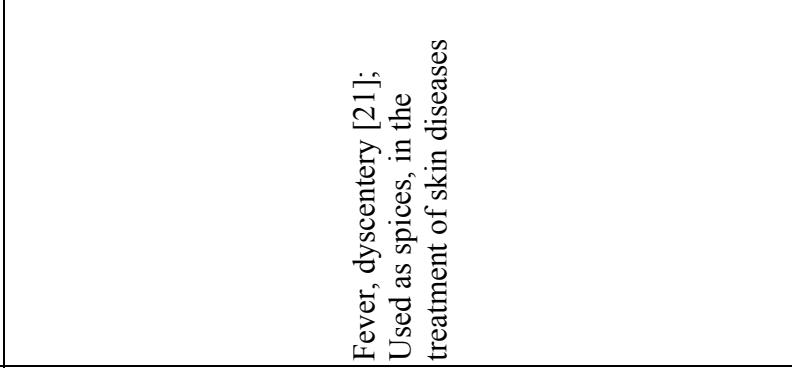 \\
\hline & 畩 & 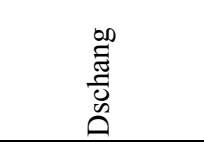 & 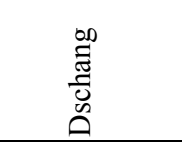 & 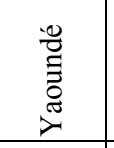 & 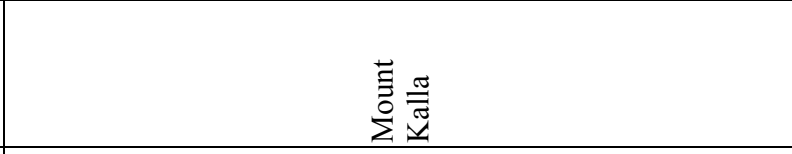 \\
\hline 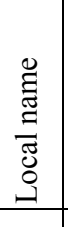 & 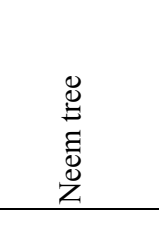 & 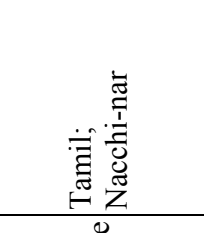 & & 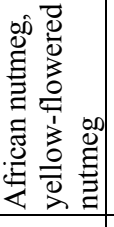 & 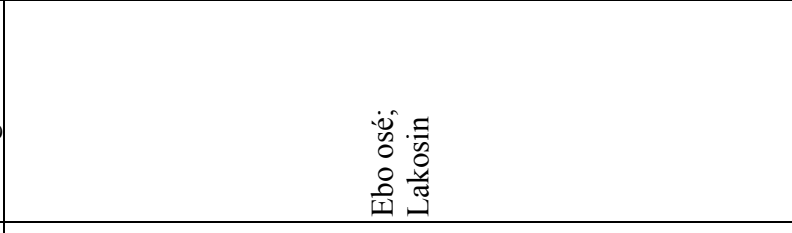 \\
\hline & 总 & 閬 & 遌 & 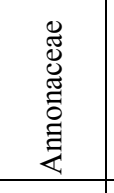 & $\underset{\mathscr{J}}{\mathscr{I}}$ \\
\hline & 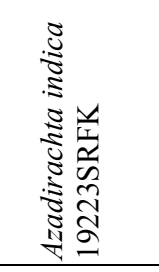 & 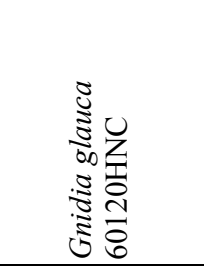 & 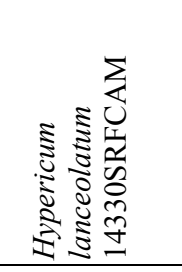 & 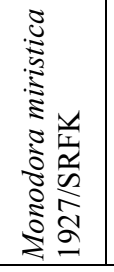 & 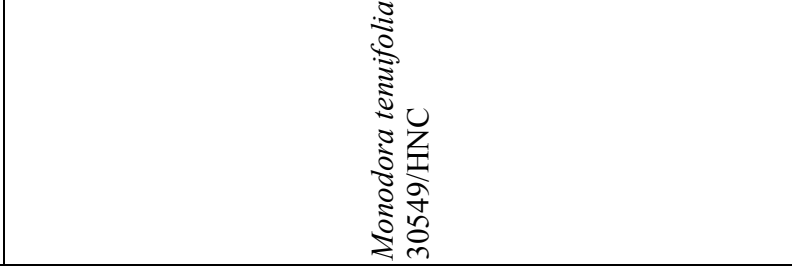 \\
\hline
\end{tabular}




\begin{tabular}{|c|c|c|c|c|c|c|c|c|}
\hline 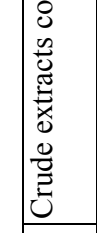 & 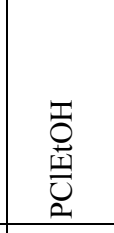 & 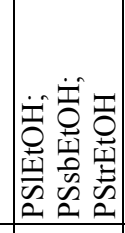 & 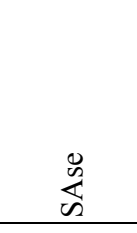 & 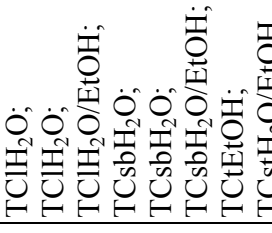 & & 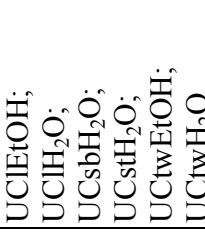 & 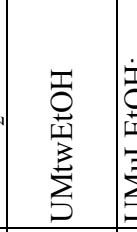 & 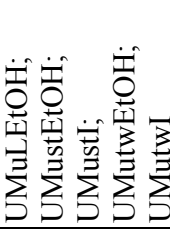 \\
\hline 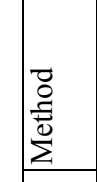 & 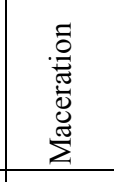 & 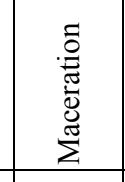 & 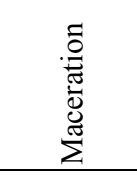 & 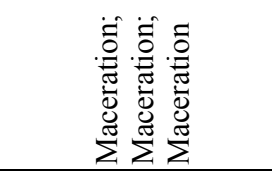 & 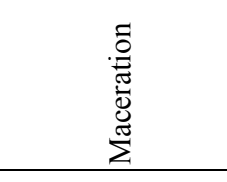 & 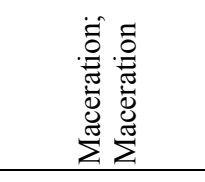 & 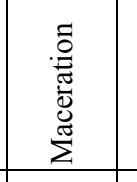 & 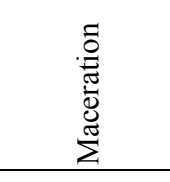 \\
\hline 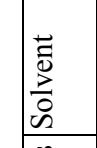 & $\begin{array}{l}\text { 总 } \\
\text { 咅 }\end{array}$ & $\begin{array}{l}\overline{\bar{o}} \\
\text { 意 } \\
\end{array}$ & 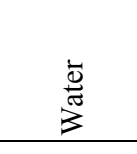 & 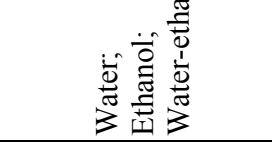 & $\begin{array}{l}\overline{\mathrm{o}} \\
\text { 意 } \\
\end{array}$ & 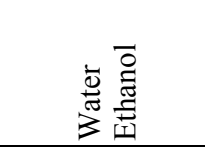 & $\begin{array}{l}\overline{\overline{0}} \\
\text { 章 }\end{array}$ & 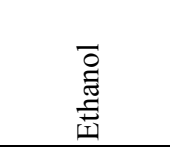 \\
\hline 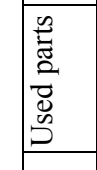 & 岕 & 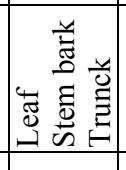 & 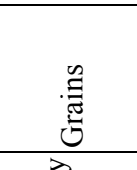 & 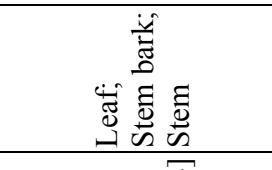 & 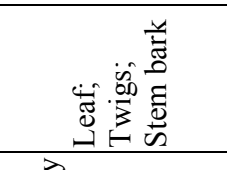 & 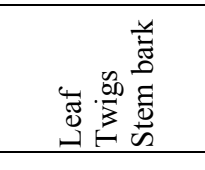 & 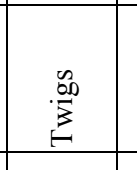 & 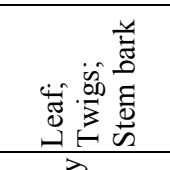 \\
\hline 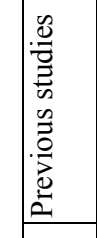 & 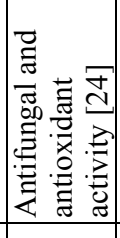 & 票要 & 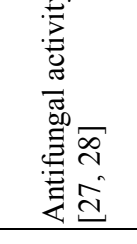 & 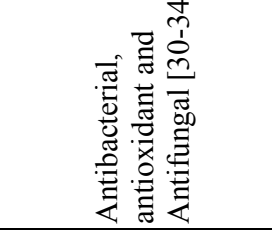 & 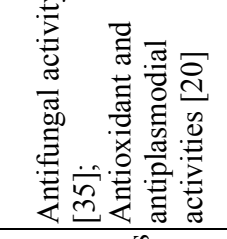 & 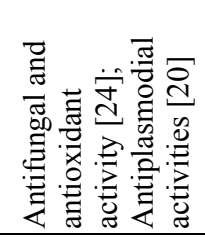 & 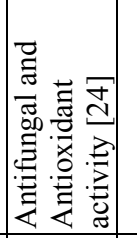 & 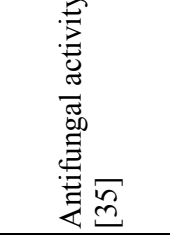 \\
\hline 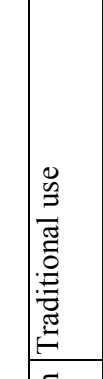 & & 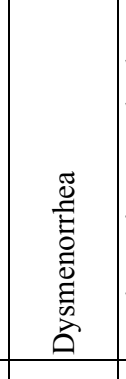 & 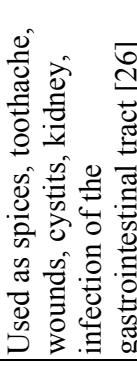 & 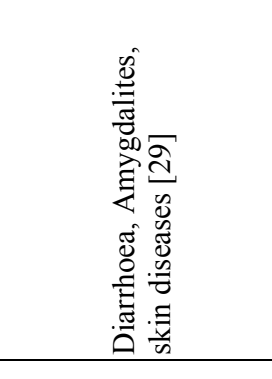 & 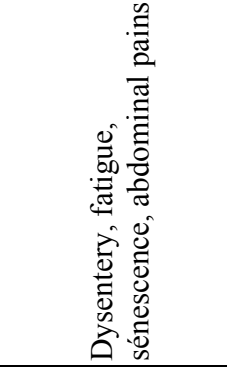 & & & 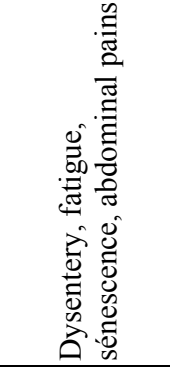 \\
\hline 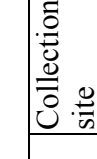 & 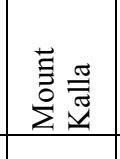 & 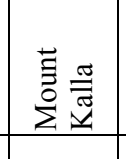 & 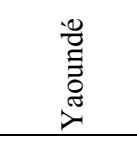 & 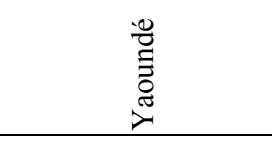 & 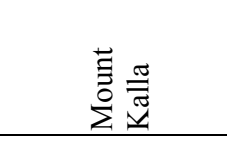 & 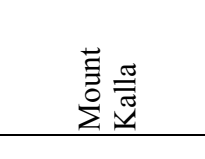 & 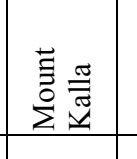 & 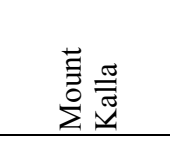 \\
\hline 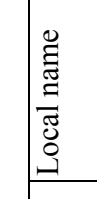 & & 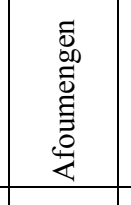 & $\stackrel{8}{0}$ & 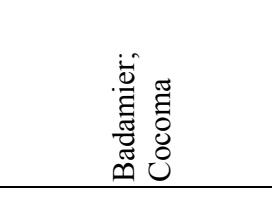 & & 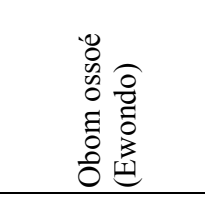 & $\begin{array}{l}\frac{0}{8} \\
\frac{0}{0} \\
\frac{0}{0} \\
0\end{array}$ & \\
\hline 差 & 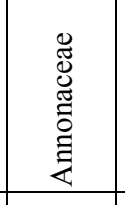 & 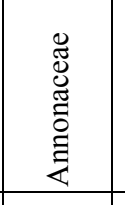 & 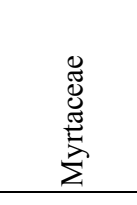 & 总 & $\begin{array}{l}\text { 章 } \\
\end{array}$ & 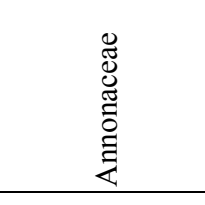 & 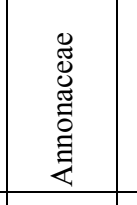 & 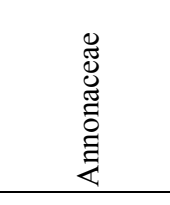 \\
\hline 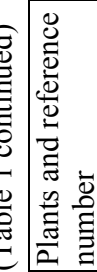 & 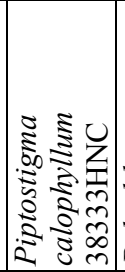 & 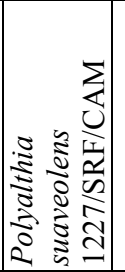 & 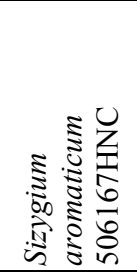 & 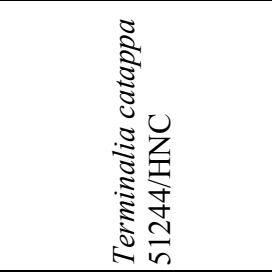 & 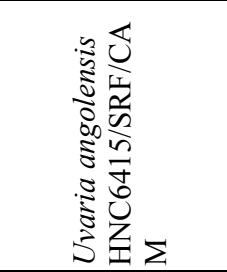 & 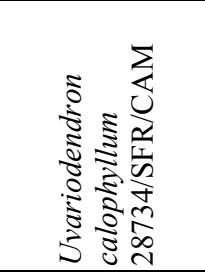 & 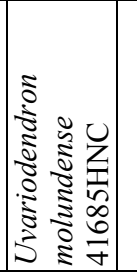 & 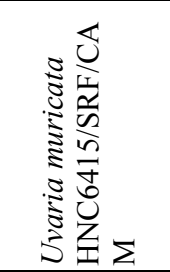 \\
\hline
\end{tabular}




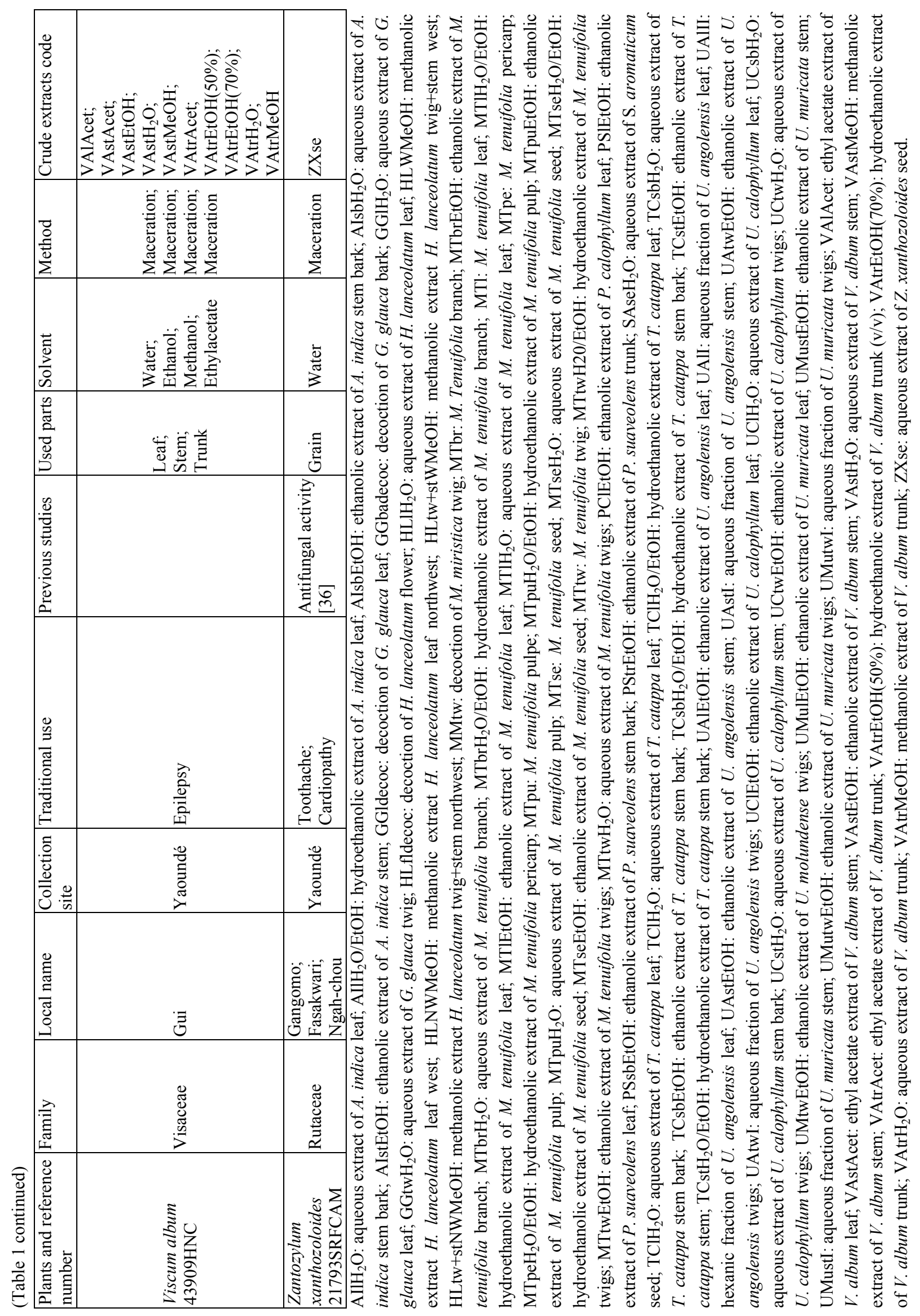


saponins, tannins, flavonoids, glucosides, phenols, alkaloids, triterpenes, anthocyanins, anthraquinones and steroids using protocols described in Refs. [37, 38].

\subsection{Antibacterial Assay}

2.3.1 Preparation of Plant Extracts Stock Solution and Antibiotic

$200 \mathrm{mg}$ of different extracts was dissolved in $2 \mathrm{~mL}$ of DMSO $10 \%$ to reach a final concentration of $100 \mathrm{mg} / \mathrm{mL}$. $250 \mathrm{mg}$ of Chloramphenicol (Mission pharma, Pharmaceutical Co. Ltd.) was dissolved in $2.5 \mathrm{~mL}$ of DMSO $10 \%$ to reach $100 \mathrm{mg} / \mathrm{mL}$. After preparation, the different stock solutions were sterilized by heating at $60{ }^{\circ} \mathrm{C}$ for $30 \mathrm{~min}$.

2.3.2 Microbial Cultures and Inoculum Preparation

Gram-positive bacteria used for the antibacterial assay included Staphylococcus aureus CIP 7625 and Gram-negatives, Pseudomonas aeruginosa CIP 76110, Salmonella typhi and Escherichia coli ATCC 25922 obtained from patients unresponsive to antibiotic treatment of the Essos Hospital Centre, Yaoundé (Cameroon). They were grown and maintained on nutrient agar slants at $35^{\circ} \mathrm{C}$ until used. They were then stored under aerobic conditions.

The inoculum was prepared from colonies collected from $18 \mathrm{~h}$ old bacterial culture with inoculating loop and suspended in sterile saline $(0.9 \% \mathrm{NaCl})$ and homogenize. The turbidity of the solution were compared to a 2-McFarland standard and adjusted to a final density of $10^{8} \mathrm{CFU} / \mathrm{mL}$ by dilution corresponding to 0.5 -McFarland standards.

2.3.3 Determination of MIC (Minimal Inhibitory Concentration)

The MIC was determined according to CLSI (Clinical Laboratory Standards Institute) M07-A9 microdilution method, using 96 wells microtitre plates. $148 \mu \mathrm{L}$ of Nutrient Broth "E" (Lab M Limited Topley House) was introduced in the wells of Column 1 $(1 \mathrm{~A}-1 \mathrm{H})$, and $100 \mu \mathrm{L}$ in the remaining wells. Later on, $52 \mu \mathrm{L}$ of stock solution of plants extracts at
$100 \mathrm{mg} / \mathrm{mL}$ were added to the first well. The medium and sample in the first well were mixed thoroughly and serially diluted by transferring $100 \mu \mathrm{L}$ from wells of Column 1 to wells of Column 2, and so until Column 11. Plant extracts concentration range from $20 \mathrm{mg} / \mathrm{mL}$ to $0.01953 \mathrm{mg} / \mathrm{mL}$. Chloramphenicol was used as positive control in each microtitre plate with the concentration ranging from $10 \mathrm{mg} / \mathrm{mL}$ to $0.09765 \mathrm{mg} / \mathrm{mL}$. Thereafter, $20 \mu \mathrm{L}$ of the inoculums were introduced each well containing the test substances except the blank consisting of wells in Column12. After an incubation period at $37^{\circ} \mathrm{C}$ for $24 \mathrm{~h}$, turbidity was observed as indication of growth. Thus, the lowest concentration inhibiting the growth of bacteria was recorded as the MIC. Each experiment was performed in duplicates.

2.3.4 Effect of Increase Inoculums Size on MIC (Minimal Inhibitory Concentration)

The extracts with MIC of less than or equal to $5 \mathrm{mg} / \mathrm{mL}$ were used to explore the effect of inoculum size two times greater than that use in the first MIC determination $\left(2 \times 10^{8} \mathrm{CFU} / \mathrm{mL}\right)$ using previously describe procedure.

\subsection{Evaluation of Synergy between the Two More Active Plant Extracts}

Decoction of G. glauca leaf and aqueous extract of $T$. catappa leaf active against the four strains were tested in combination. A two-dimensional, two-agent broth microdilution checkerboard technique was used to study the interaction between the two extracts. The FIC (fractional inhibitory concentration) was derived from the lowest concentration of extracts in combination permitting no visible growth of the test organisms. FICI (FIC index) is calculated as the sum of the FICs of each agent. A FICI of $\leq 0.5$ indicates synergistic interaction; $>0.5$ but $\leq 1$, additive interaction; $>1$ but $\leq 4$, indifferent interaction; and $>4$, antagonistic interaction. The FIC of each agent is calculated as the MIC of the agent in combination divided by the MIC of the agent [39]. 


\section{Results}

The different results were statistically analysed using the software SPSS 17.0 for windows and variance analysis by ANOVA coupled with Turkey test, where $p<0.05$ was considered as statistically significant.

\subsection{Minimal Inhibitory Concentration of Extracts}

The MIC ranged from 0.625 to $20 \mathrm{mg} / \mathrm{mL}$ (Table 2) and vary with plants materials, plants part and extraction procedure. The most active extract from these plant are ethanolic extract of $A$. indica stem, aqueous extract of $T$. catappa leaves and decoction of G. glauca leaves. This activity could be due to the nature of secondary metabolites present in the plant part and the solvent used for extraction. In fact, the capacity of extraction and solubilisation of solvent is different towards the secondary metabolites.

Twenty extracts inhibited the growth of the four strains at $\mathrm{MIC} \leq 5 \mathrm{mg} / \mathrm{mL}$. Out of 81 extracts tested eight (AIsbEtOH, AIstEtOH, GGldecoc, TCl water, $\mathrm{TCH}_{2} \mathrm{O} / \mathrm{EtOH}, \quad \mathrm{TClEtOH}, \quad \mathrm{TCsbEtOH}$ and $\mathrm{TCtwH}_{2} \mathrm{O} / \mathrm{EtOH}$ ) with MIC less or equal to $2.5 \mathrm{mg} / \mathrm{mL}$ on four strains were selected to determine the effect of double size inoculum (Table 3).

The MIC of the eight tested extracts ranged from 2.5 to $10 \mathrm{mg} / \mathrm{mL}$ (Table 3). Seven extracts inhibited the growth of the four strains with $\leq 5 \mathrm{mg} / \mathrm{mL}$ and one extract inhibited with $10 \mathrm{mg} / \mathrm{mL}$ on three strains. The extracts with $\mathrm{MIC} \leq 2.5 \mathrm{mg} / \mathrm{mL}$ on the four strains were selected and tested for combination consisting of GGldecoc (decoction of G. glauca leaf) and $\mathrm{TClH}_{2} \mathrm{O}$ (aqueous extract of $T$. catappa leaf).

\subsection{MIC (Minimal Inhibitory Concentration) of Extract Combination Tests}

The checkerboard assay was conducted using the decoction of G. glauca leaf and aqueous extract of $T$. catappa leaf against bacteria strains (Table 4). This method supports evidence for synergy, competition or antagonism for selected compounds as it is reflected by the FICI. A FICI of $\leq 0.5$ indicates synergistic interaction. These plant extracts increased their respective antibacterial activity against the tested strains. Synergism effect was observed on Escherichia coli, Pseudomonas aeruginosa, Salmonella typhi and additive effect on Staphylococcus aureus with the two plant extracts. The mean FIC indices ranged from 0.33 to 0.68 on the four bacteria strains (Table 4 ).

\subsection{Phytochemical Composition of the Two Extracts}

Phytochemical screening revealed the presence of saponins, tannins, glucosides, phenols, triterpenes and anthraquinones in both extracts. Alkaloids and steroids were present only in the aqueous extract of $T$. catappa leaf and flavonoids in the decoction of G. glauca leaf (Table 5).

\section{Discussion}

This study was carried out on various plant extracts chosen on the ethnopharmacological basis where their efficacy for century's usage was verified in many cases by scientific studies (Table 1). The antibacterial evaluation of 81 extracts from 15 plants revealed a significant potency against four bacterial strains which varied with plants, plant parts, extraction procedures and bacterial strains. Although it is evident that many constituents within plants interact, it should also be noted that other interactions may occur between groups of molecules from plant part or between different plants species. Besides, traditional healers in the world particularly in Africa often combine various plant part or plant species in order to enhance their efficacy by possible synergistic interaction between different groups of bioactive compounds.

T. catappa and G. glauca combination was tested against bacteria and the FICI values showed synergistic and additive effect on the four bacterial strains. These interactions (synergistic and additive) result from the combined effect of active constituents from each extract. Apart from flavonoids found in the aqueous extract of T. catappa, both extracts used in combination 

Escherichia coli, Pseudomonas aeruginosa and Salmonella typhi

Table 2 MIC (minimal inhibitory concentration) values of extracts against four bacteria (units in $\mathbf{m g} / \mathbf{m L}$ ).

\begin{tabular}{|c|c|c|c|c|}
\hline Extracts & Staphylococcus aureus & Pseudomonas aeruginosa & Escherichia coli & Salmonella typhi \\
\hline VAlAcet & $20.00 \pm 0.00$ & $10.00 \pm 0.00$ & $20.00 \pm 0.00$ & $10.00 \pm 0.00$ \\
\hline VAstAcet & $10.00 \pm 0.00$ & $>20.00 \pm 0.00$ & $>20.00 \pm 0.00$ & $>20.00 \pm 0.00$ \\
\hline VAstEtOH & $20.00 \pm 0.00$ & $10.00 \pm 0.00$ & $10.00 \pm 0.00$ & $20.00 \pm 0.00$ \\
\hline $\mathrm{VAstH}_{2} \mathrm{O}$ & $10.00 \pm 0.00$ & $5.00 \pm 0.00$ & $5.00 \pm 0.00$ & $10.00 \pm 0.00$ \\
\hline VAstMeOH & $20.00 \pm 0.00$ & $10.00 \pm 0.00$ & $10.00 \pm 0.00$ & $20.00 \pm 0.00$ \\
\hline VAtrAcet & $>20.00 \pm 0.00$ & $>20.00 \pm 0.00$ & $20.00 \pm 0.00$ & $20.00 \pm 0.00$ \\
\hline VAtrEtOH(50\%) & $>20.00 \pm 0.00$ & $10.00 \pm 0.00$ & $20.00 \pm 0.00$ & $20.00 \pm 0.00$ \\
\hline VAtrEtOH(70\%) & $10.00 \pm 0.00$ & $5.00 \pm 0.00$ & $5.00 \pm 0.00$ & $5.00 \pm 0.00$ \\
\hline VAtr $\mathrm{H}_{2} \mathrm{O}$ & $10.00 \pm 0.00$ & $10.00 \pm 0.00$ & $10.00 \pm 0.00$ & $10.00 \pm 0.00$ \\
\hline VAtrMeOH & $20.00 \pm 0.00$ & $10.00 \pm 0.00$ & $10.00 \pm 0.00$ & $10.00 \pm 0.00$ \\
\hline $\mathrm{AIlH}_{2} \mathrm{O}$ & $10.00 \pm 0.00$ & $2.50 \pm 0.00$ & $10.00 \pm 0.00$ & $10.00 \pm 0.00$ \\
\hline $\mathrm{AIlH}_{2} \mathrm{O} / \mathrm{EtOH}$ & $10.00 \pm 0.00$ & $5.00 \pm 0.00$ & $10.00 \pm 0.00$ & $10.00 \pm 0.00$ \\
\hline AIsbEtOH & $2.50 \pm 0.00$ & $5.00 \pm 0.00$ & $2.50 \pm 0.00$ & $1.25 \pm 0.00$ \\
\hline $\mathrm{AIsbH}_{2} \mathrm{O}$ & $2.50 \pm 0.00$ & $5.00 \pm 0.00$ & $10.00 \pm 0.00$ & $2.50 \pm 0.00$ \\
\hline AIstEtOH & $2.50 \pm 0.00$ & $5.00 \pm 0.00$ & $1.25 \pm 0.00$ & $1.25 \pm 0.00$ \\
\hline GGbadecoc & $5.00 \pm 0.00$ & $5.00 \pm 0.00$ & $5.00 \pm 0.00$ & $5.00 \pm 0.00$ \\
\hline $\mathrm{GGlH}_{2} \mathrm{O}$ & $5.00 \pm 0.00$ & $5.00 \pm 0.00$ & $5.00 \pm 0.00$ & $5.00 \pm 0.00$ \\
\hline GGldecoc & $5.00 \pm 0.00$ & $2.50 \pm 0.00$ & $2.50 \pm 0.00$ & $2.50 \pm 0.00$ \\
\hline $\mathrm{GGtwH}_{2} \mathrm{O}$ & $5.00 \pm 0.00$ & $5.00 \pm 0.00$ & $10.00 \pm 0.00$ & $5.00 \pm 0.00$ \\
\hline HLfldecoc & $5.00 \pm 0.00$ & $5.00 \pm 0.00$ & $5.00 \pm 0.00$ & $5.00 \pm 0.00$ \\
\hline $\mathrm{HLlH}_{2} \mathrm{O}$ & $5.00 \pm 0.00$ & $5.00 \pm 0.00$ & $10.00 \pm 0.00$ & $10.00 \pm 0.00$ \\
\hline HLIWMeOH & $5.00 \pm 0.00$ & $5.00 \pm 0.00$ & $5.00 \pm 0.00$ & $10.00 \pm 0.00$ \\
\hline HLINWMeOH & $10.00 \pm 0.00$ & $20.00 \pm 0.00$ & $5.00 \pm 0.00$ & $20.00 \pm 0.00$ \\
\hline HLtw+stWMeOH & $20.00 \pm 0.00$ & $20.00 \pm 0.00$ & $20.00 \pm 0.00$ & $20.00 \pm 0.00$ \\
\hline HyLtw+stSWMeOH & $20.00 \pm 0.00$ & $20.00 \pm 0.00$ & $20.00 \pm 0.00$ & $20.00 \pm 0.00$ \\
\hline MMtwdecoc & $20.00 \pm 0.00$ & $5.00 \pm 0.00$ & $10.00 \pm 0.00$ & $20.00 \pm 0.00$ \\
\hline MTbr & $5.00 \pm 0.00$ & $5.00 \pm 0.00$ & $5.00 \pm 0.00$ & $10.00 \pm 0.00$ \\
\hline MTbrEtOH & $10.00 \pm 0.00$ & $5.00 \pm 0.00$ & $1.25 \pm 0.00$ & $20.00 \pm 0.00$ \\
\hline $\mathrm{MTbrH}_{2} \mathrm{O}$ & $10.00 \pm 0.00$ & $10.00 \pm 0.00$ & $10.00 \pm 0.00$ & $5.00 \pm 0.00$ \\
\hline $\mathrm{MTbrH}_{2} \mathrm{O} / \mathrm{EtOH}$ & $10.00 \pm 0.00$ & $5.00 \pm 0.00$ & $5.00 \pm 0.00$ & $5.00 \pm 0.00$ \\
\hline MT1 & $5.00 \pm 0.00$ & $5.00 \pm 0.00$ & $10.00 \pm 0.00$ & $10.00 \pm 0.00$ \\
\hline $\mathrm{MTlH}_{2} \mathrm{O} / \mathrm{EtOH}$ & $10.00 \pm 0.00$ & $5.00 \pm 0.00$ & $2.50 \pm 0.00$ & $20.00 \pm 0.00$ \\
\hline MTlEtOH & $>20.00 \pm 0.00$ & $>20.00 \pm 0.00$ & $>20.00 \pm 0.00$ & $>20.00 \pm 0.00$ \\
\hline $\mathrm{MTlH}_{2} \mathrm{O}$ & $5.00 \pm 0.00$ & $5.00 \pm 0.00$ & $2.50 \pm 0.00$ & $2.50 \pm 0.00$ \\
\hline MTpe & $10.00 \pm 0.00$ & $5.00 \pm 0.00$ & $20.00 \pm 0.00$ & $20.00 \pm 0.00$ \\
\hline $\mathrm{MTpeH}_{2} \mathrm{O} / \mathrm{EtOH}$ & $10.00 \pm 0.00$ & $10.00 \pm 0.00$ & $20.00 \pm 0.00$ & $20.00 \pm 0.00$ \\
\hline MTpu & $10.00 \pm 0.00$ & $10.00 \pm 0.00$ & $10.00 \pm 0.00$ & $5.00 \pm 0.00$ \\
\hline $\mathrm{MTpuH}_{2} \mathrm{O} / \mathrm{EtOH}$ & $10.00 \pm 0.00$ & $>20.00 \pm 0.00$ & $5.00 \pm 0.00$ & $20.00 \pm 0.00$ \\
\hline MTpuEtOH & $>20.00 \pm 0.00$ & $10.00 \pm 0.00$ & $10.00 \pm 0.00$ & $>20.00 \pm 0.00$ \\
\hline $\mathrm{MTpuH}_{2} \mathrm{O}$ & $20.00 \pm 0.00$ & $20.00 \pm 0.00$ & $10.00 \pm 0.00$ & $10.00 \pm 0.00$ \\
\hline MTse & $10.00 \pm 0.00$ & $10.00 \pm 0.00$ & $20.00 \pm 0.00$ & $20.00 \pm 0.00$ \\
\hline $\mathrm{MTseH}_{2} \mathrm{O}$ & $10.00 \pm 0.00$ & $20.00 \pm 0.00$ & $5.00 \pm 0.00$ & $5.00 \pm 0.00$ \\
\hline $\mathrm{MTseH}_{2} \mathrm{O} / \mathrm{EtOH}$ & $>20.00 \pm 0.00$ & $>20.00 \pm 0.00$ & $>20.00 \pm 0.00$ & $>20.00 \pm 0.00$ \\
\hline MTseEtOH & $10.00 \pm 0.00$ & $>20.00 \pm 0.00$ & $>20.00 \pm 0.00$ & $>20.00 \pm 0.00$ \\
\hline MTtw & $5.00 \pm 0.00$ & $5.00 \pm 0.00$ & $5.00 \pm 0.00$ & $5.00 \pm 0.00$ \\
\hline MTtwH2O/EtOH & $5.00 \pm 0.00$ & $2.50 \pm 0.00$ & $5.00 \pm 0.00$ & $2.50 \pm 0.00$ \\
\hline MTtwEtOH & $>20.00 \pm 0.00$ & $>20.00 \pm 0.00$ & $20.00 \pm 0.00$ & $>20.00 \pm 0.00$ \\
\hline $\mathrm{MTtwH}_{2} \mathrm{O}$ & $10.00 \pm 0.00$ & $10.00 \pm 0.00$ & $10.00 \pm 0.00$ & $5.00 \pm 0.00$ \\
\hline PClEtOH & $10.00 \pm 0.00$ & $20.00 \pm 0.00$ & $20.00 \pm 0.00$ & $10.00 \pm 0.00$ \\
\hline PSlEtOH & $>20.00 \pm 0.00$ & $>20.00 \pm 0.00$ & $>20.00 \pm 0.00$ & $>20.00 \pm 0.00$ \\
\hline PSsbEtOH & $20.00 \pm 0.00$ & $20.00 \pm 0.00$ & $10.00 \pm 0.00$ & $5.00 \pm 0.00$ \\
\hline PStrEtOH & $>20.00 \pm 0.00$ & $20.00 \pm 0.00$ & $>20.00 \pm 0.00$ & $20.00 \pm 0.00$ \\
\hline SAse & $2.50 \pm 0.00$ & $1.25 \pm 0.00$ & $2.50 \pm 0.00$ & $10.00 \pm 0.00$ \\
\hline $\mathrm{TClH}_{2} \mathrm{O}$ & $5.00 \pm 0.00$ & $1.25 \pm 0.00$ & $0.625 \pm 0.00$ & $2.50 \pm 0.00$ \\
\hline
\end{tabular}



Escherichia coli, Pseudomonas aeruginosa and Salmonella typhi

(Table 2 continued)

\begin{tabular}{|c|c|c|c|c|}
\hline Extracts & Staphylococcus aureus & Pseudomonas aeruginosa & Escherichia coli & Salmonella typhi \\
\hline $\mathrm{TClH}_{2} \mathrm{O}$ & $1.25 \pm 0.00$ & $2.50 \pm 0.00$ & $1.25 \pm 0.00$ & $2.50 \pm 0.00$ \\
\hline $\mathrm{TClH}_{2} \mathrm{O} / \mathrm{EtOH}$ & $1.25 \pm 0.00$ & $2.50 \pm 0.00$ & $2.50 \pm 0.00$ & $2.50 \pm 0.00$ \\
\hline $\mathrm{TCsbH}_{2} \mathrm{O}$ & $2.50 \pm 0.00$ & $2.50 \pm 0.00$ & $1.25 \pm 0.00$ & $1.25 \pm 0.00$ \\
\hline $\mathrm{TCsbH}_{2} \mathrm{O}$ & $2.50 \pm 0.00$ & $5.00 \pm 0.00$ & $2.50 \pm 0.00$ & $2.50 \pm 0.00$ \\
\hline $\mathrm{TCsbH}_{2} \mathrm{O} / \mathrm{EtOH}$ & $10.00 \pm 0.00$ & $5.00 \pm 0.00$ & $20.00 \pm 0.00$ & $5.00 \pm 0.00$ \\
\hline TCstEtOH & $5.00 \pm 0.00$ & $5.00 \pm 0.00$ & $10.00 \pm 0.00$ & $2.50 \pm 0.00$ \\
\hline $\mathrm{TCstH}_{2} \mathrm{O} / \mathrm{EtOH}$ & $5.00 \pm 0.00$ & $1.25 \pm 0.00$ & $1.25 \pm 0.00$ & $2.50 \pm 0.00$ \\
\hline UClEtOH & $20.00 \pm 0.00$ & $20.00 \pm 0.00$ & $20.00 \pm 0.00$ & $20.00 \pm 0.00$ \\
\hline $\mathrm{UClH}_{2} \mathrm{O}$ & $10.00 \pm 0.00$ & $5.00 \pm 0.00$ & $5.00 \pm 0.00$ & $10.00 \pm 0.00$ \\
\hline $\mathrm{UCsbH}_{2} \mathrm{O}$ & $5.00 \pm 0.00$ & $2.50 \pm 0.00$ & $2.50 \pm 0.00$ & $2.50 \pm 0.00$ \\
\hline $\mathrm{UCstH}_{2} \mathrm{O}$ & $5.00 \pm 0.00$ & $2.50 \pm 0.00$ & $2.50 \pm 0.00$ & $2.50 \pm 0.00$ \\
\hline UCtwEtOH & $5.00 \pm 0.00$ & $2.50 \pm 0.00$ & $2.50 \pm 0.00$ & $5.00 \pm 0.00$ \\
\hline $\mathrm{UCtwH}_{2} \mathrm{O}$ & $5.00 \pm 0.00$ & $2.50 \pm 0.00$ & $5.00 \pm 0.00$ & $5.00 \pm 0.00$ \\
\hline UMtwEtOH & $5.00 \pm 0.00$ & $5.00 \pm 0.00$ & $5.00 \pm 0.00$ & $5.00 \pm 0.00$ \\
\hline UMuLEtOH & $5.00 \pm 0.00$ & $5.00 \pm 0.00$ & $10.00 \pm 0.00$ & $20.00 \pm 0.00$ \\
\hline UMustEtOH & $10.00 \pm 0.00$ & $5.00 \pm 0.00$ & $10.00 \pm 0.00$ & $20.00 \pm 0.00$ \\
\hline UMustI & $5.00 \pm 0.00$ & $5.00 \pm 0.00$ & $5.00 \pm 0.00$ & $20.00 \pm 0.00$ \\
\hline UMutwEtOH & $>20.00 \pm 0.00$ & $>20.00 \pm 0.00$ & $>20.00 \pm 0.00$ & $>20.00 \pm 0.00$ \\
\hline UMutwI & $20.00 \pm 0.00$ & $10.00 \pm 0.00$ & $10.00 \pm 0.00$ & $20.00 \pm 0.00$ \\
\hline UALEtOH & $10.00 \pm 0.00$ & $20.00 \pm 0.00$ & $20.00 \pm 0.00$ & $10.00 \pm 0.00$ \\
\hline UALI & $10.00 \pm 0.00$ & $5.00 \pm 0.00$ & $10.00 \pm 0.00$ & $10.00 \pm 0.00$ \\
\hline UALII & $2.50 \pm 0.00$ & $5.00 \pm 0.00$ & $5.00 \pm 0.00$ & $10.00 \pm 0.00$ \\
\hline UAstEtOH & $20.00 \pm 0.00$ & $5.00 \pm 0.00$ & $10.00 \pm 0.00$ & $20.00 \pm 0.00$ \\
\hline UAstI & $5.00 \pm 0.00$ & $10.00 \pm 0.00$ & $5.00 \pm 0.00$ & $20.00 \pm 0.00$ \\
\hline UAtwEtOH & $10.00 \pm 0.00$ & $10.00 \pm 0.00$ & $2.50 \pm 0.00$ & $>20.00 \pm 0.00$ \\
\hline UAtwI & $10.00 \pm 0.00$ & $2.50 \pm 0.00$ & $2.50 \pm 0.00$ & $10.00 \pm 0.00$ \\
\hline ZXse & $5.00 \pm 0.00$ & $2.50 \pm 0.00$ & $5.00 \pm 0.00$ & $10.00 \pm 0.00$ \\
\hline Chloramphenicol & $2.50 \pm 0.00$ & $>10.00 \pm 0.00$ & $>10.00 \pm 0.00$ & $5.00 \pm 0.00$ \\
\hline
\end{tabular}

Results are expressed as mean \pm standard deviation; $\mathrm{AIlH}_{2} \mathrm{O}$ : aqueous extract of $A$. indica leaf; $\mathrm{AIlH}_{2} \mathrm{O} / \mathrm{EtOH}$ : hydroethanolic extract of $A$. indica leaf; AIsbEtOH: ethanolic extract of $A$. indica stem bark; $\mathrm{AIsbH}_{2} \mathrm{O}$ : aqueous extract of $A$. indica stem bark; AIstEtOH: ethanolic extract of A. indica stem; GGldecoc: decoction of G.glauca leaf; GGbadecoc: decoction of G. glauca bark; $\mathrm{GGlH}_{2} \mathrm{O}$ : aqueous extract of G. glauca leaf; $\mathrm{GGtwH}_{2} \mathrm{O}$ : aqueous extract of G. glauca twig; HLfldecoc: decoction of H. lanceolatum flower; $\mathrm{HLlH}_{2} \mathrm{O}$ : aqueous extract of $H$. lanceolatum leaf; $\mathrm{HLWMeOH}$ : methanolic extract $H$. lanceolatum leaf west; HLNWMeOH: methanolic extract $H$. lanceolatum leaf northwest; HLtw+stWMeOH: methanolic extract H. lanceolatum twig+stem west; HLtw+stNWMeOH: methanolic extract H. lanceolatum twig+stem northwest; MMtw: decoction of M. miristica twig; MTbr: M. Tenuifolia branch; MTbrEtOH: ethanolic extract of $M$. tenuifolia branch; $\mathrm{MTbrH}_{2} \mathrm{O}$ : aqueous extract of M. tenuifolia branch; $\mathrm{MTbrH}_{2} \mathrm{O} / \mathrm{EtOH}$ : hydroethanolic extract of $M$. tenuifolia branch; MTl: M. tenuifolia leaf; $\mathrm{MTlH}_{2} \mathrm{O} / \mathrm{EtOH}$ : hydroethanolic extract of $M$. tenuifolia leaf; MTlEtOH: ethanolic extract of $M$. tenuifolia leaf; $\mathrm{MTlH}_{2} \mathrm{O}$ : aqueous extract of $M$. tenuifolia leaf; MTpe: M. tenuifolia pericarp; $\mathrm{MTpeH}_{2} \mathrm{O} / \mathrm{EtOH}$ : hydroethanolic extract of $M$. tenuifolia pericarp; $\mathrm{MTpu}$ : M. tenuifolia pulpe; $\mathrm{MTpuH} \mathrm{H}_{2} \mathrm{O} / \mathrm{EtOH}$ : hydroethanolic extract of $M$. tenuifolia pulp; MTpuEtOH: ethanolic extract of M. tenuifolia pulp; $\mathrm{MTpuH}_{2} \mathrm{O}$ : aqueous extract of $M$. tenuifolia pulp; MTse: M. tenuifolia seed; $\mathrm{MTseH}_{2} \mathrm{O}$ : aqueous extract of $M$. tenuifolia seed; $\mathrm{MTseH}_{2} \mathrm{O} / \mathrm{EtOH}$ : hydroethanolic extract of M. tenuifolia seed; MTseEtOH: ethanolic extract of M. tenuifolia seed; MTtw: M. tenuifolia twig; $\mathrm{MTtwH}_{2} \mathrm{O} / \mathrm{EtOH}$ : hydroethanolic extract of M. tenuifolia twigs; MTtwEtOH: ethanolic extract of $M$. tenuifolia twigs; $\mathrm{MTtwH}_{2} \mathrm{O}$ : aqueous extract of $M$. tenuifolia twigs; PCIEtOH: ethanolic extract of $P$. calophyllum leaf; PSIEtOH: ethanolic extract of $P$. suaveolens leaf; PSsbEtOH: ethanolic extract of $P$. suaveolens stem bark; PStrEtOH: ethanolic extract of $P$. suaveolens trunk; $\mathrm{SAseH}_{2} \mathrm{O}$ : aqueous extract of S. aromaticum seed; $\mathrm{TClH}_{2} \mathrm{O}$ : aqueous extract of $T$. catappa leaf; $\mathrm{TClH}_{2} \mathrm{O}$ : aqueous extract of $T$. catappa leaf; $\mathrm{TClH}_{2} \mathrm{O} / \mathrm{EtOH}$ : hydroethanolic extract of $T$. catappa leaf; $\mathrm{TCsbH}_{2} \mathrm{O}$ : aqueous extract of T. catappa stem bark; TCsbEtOH: ethanolic extract of T. catappa stem bark; $\mathrm{TCsbH} \mathrm{H}_{2} \mathrm{O} / \mathrm{EtOH}$ : hydroethanolic extract of T. catappa stem bark; TCstEtOH: ethanolic extract of $T$. catappa stem; $\mathrm{TCstH}_{2} \mathrm{O} / \mathrm{EtOH}$ : hydroethanolic extract of T. catappa stem bark; UAlEtOH: ethanolic extract of $U$. angolensis leaf; UAlI: aqueous fraction of $U$. angolensis leaf; UAlII: hexanic fraction of $U$. angolensis leaf; UAstEtOH: ethanolic extract of $U$. angolensis stem; UAstI: aqueous fraction of $U$. angolensis stem; UAtwEtOH: ethanolic extract of $U$. angolensis twigs; UAtwI: aqueous fraction of $U$. angolensis twigs; UClEtOH: ethanolic extract of $U$. calophyllum leaf; $\mathrm{UClH}_{2} \mathrm{O}$ : aqueous extract of $U$. calophyllum leaf; $\mathrm{UCsbH}_{2} \mathrm{O}$ : aqueous extract of $U$. calophyllum stem 

Escherichia coli, Pseudomonas aeruginosa and Salmonella typhi

bark; $\mathrm{UCstH}_{2} \mathrm{O}$ : aqueous extract of $U$. calophyllum stem; $\mathrm{UCtwEtOH}$ : ethanolic extract of U. calophyllum twigs; $\mathrm{UCtwH}_{2} \mathrm{O}$ : aqueous extract of $U$. calophyllum twigs; UMtwEtOH: ethanolic extract of $U$. Molundense twigs; UMulEtOH: ethanolic extract of $U$. muricata leaf; UMustEtOH: ethanolic extract of U. muricata stem; UMustI: aqueous fraction of U. muricata stem; UMutwEtOH: ethanolic extract of $U$. muricata twigs; UMutwI: aqueous fraction of $U$. muricata twigs; VAlAcet: ethyl acetate extract of $V$. album leaf; VAstAcet: ethyl acetate extract of $V$. album stem; VAstEtOH: ethanolic extract of $V$. album stem; $\mathrm{VAstH}_{2} \mathrm{O}$ : aqueous extract of $V$. album stem; VAstMeOH: methanolic extract of $V$. album stem; VAtrAcet: ethyl acetate extract of $V$. album trunk; VAtrEtOH(50\%): hydroethanolic extract of $V$. album trunk (v/v); VAtrEtOH(70\%): hydroethanolic extract of V. album trunk; VAtrH $\mathrm{O}_{2} \mathrm{O}$ : aqueous extract of $V$. album trunk; VAtrMeOH: methanolic extract of $V$. album trunk; ZXse: aqueous extract of Z. xanthozoloides seed.

Table 3 MIC values of the eight extracts on double inoculum size of the four bacteria strains.

\begin{tabular}{|c|c|c|c|c|}
\hline Extracts & Staphylococcus aureus & Pseudomonas aeruginosa & Escherichia coli & Salmonella typhi \\
\hline AIsbEtOH & $5.00 \pm 0.00$ & $5.00 \pm 0.00$ & $2.50 \pm 0.00$ & $5.00 \pm 0.00$ \\
\hline AIstEtOH & $5.00 \pm 0.00$ & $10.00 \pm 0.00$ & $10.00 \pm 0.00$ & $10.00 \pm 0.00$ \\
\hline GGldecoc & $2.50 \pm 0.00$ & $2.50 \pm 0.00$ & $2.50 \pm 0.00$ & $2.50 \pm 0.00$ \\
\hline $\mathrm{TClH}_{2} \mathrm{O}$ & $2.50 \pm 0.00$ & $2.50 \pm 0.00$ & $2.50 \pm 0.00$ & $2.50 \pm 0.00$ \\
\hline $\mathrm{TClH}_{2} \mathrm{O} / \mathrm{EtOH}$ & $5.00 \pm 0.00$ & $5.00 \pm 0.00$ & $5.00 \pm 0.00$ & $2.50 \pm 0.00$ \\
\hline TClEtOH & $5.00 \pm 0.00$ & $5.00 \pm 0.00$ & $5.00 \pm 0.00$ & $5.00 \pm 0.00$ \\
\hline TCsbEtOH & $5.00 \pm 0.00$ & $5.00 \pm 0.00$ & $2.50 \pm 0.00$ & $2.50 \pm 0.00$ \\
\hline $\mathrm{TCstH}_{2} \mathrm{O} / \mathrm{EtOH}$ & $5.00 \pm 0.00$ & $2.50 \pm 0.00$ & $2.50 \pm 0.00$ & $2.50 \pm 0.00$ \\
\hline
\end{tabular}

Results are expressed as mean \pm standard deviation; $\mathrm{TClH}_{2} \mathrm{O}$ : aqueous extract of $T$. catappa leaf; $\mathrm{TClH}_{2} \mathrm{O} / \mathrm{EtOH}$ : hydroethanolic extract of T. catappa leaf; TCsbEtOH: ethanolic extract of T. catappa stem bark; $\mathrm{TCstH}_{2} \mathrm{O} / \mathrm{EtOH}$ : hydroethanolic extract of $T$. catappa stem bark; AIsbEtOH: ethanolic extract of A. indicastem bark; AIstEtOH: ethanolic extract of A. indicastem; GGldecoc: decoction of G. glauca leaf.

Table 4 FICI of GGldecoc/ $\mathrm{TCIH}_{2} \mathrm{O}$ combination against four bacteria strains.

\begin{tabular}{|c|c|c|c|c|c|}
\hline \multicolumn{6}{|c|}{ Four bacteria strains } \\
\hline \multirow{4}{*}{$\begin{array}{l}\text { Staphylococcus } \\
\text { aureus }\end{array}$} & FIC GGldecoc & $0.25 \pm 0.00$ & $0.50 \pm 0.00$ & $0.50 \pm 0.00$ & $0.50 \pm 0.00$ \\
\hline & FIC $\mathrm{TClH}_{2} \mathrm{O}$ & $0.50 \pm 0.00$ & $0.25 \pm 0.00$ & $0.13 \pm 0.00$ & $1.00 \pm 0.00$ \\
\hline & FICI $(\Sigma$ FIC $)$ & $0.75 \pm 0.00$ & $0.75 \pm 0.00$ & $0.63 \pm 0.00$ & $1.50 \pm 0.00$ \\
\hline & Average of FICI (interpretation) & \multicolumn{4}{|c|}{0.9062 (additive) } \\
\hline \multirow{4}{*}{ Escherichia coli } & FIC GGldecoc & $0.063 \pm 0.00$ & $0.063 \pm 0.00$ & $0.13 \pm 0.00$ & - \\
\hline & FIC $\mathrm{TClH}_{2} \mathrm{O}$ & $0.50 \pm 0.00$ & $0.13 \pm 0.00$ & $0.13 \pm 0.00$ & - \\
\hline & FICI $(\Sigma F I C)$ & $0.56 \pm 0.00$ & $0.18 \pm 0.00$ & $0.25 \pm 0.00$ & - \\
\hline & Average of FICI (interpretation) & \multicolumn{4}{|c|}{0.3333 (synergy) } \\
\hline \multirow{4}{*}{$\begin{array}{l}\text { Pseudomonas } \\
\text { aeruginosa }\end{array}$} & FIC GGldecoc & $0.03 \pm 0.00$ & $0.25 \pm 0.00$ & $0.25 \pm 0.00$ & - \\
\hline & FIC $\mathrm{TClH}_{2} \mathrm{O}$ & $0.50 \pm 0.00$ & $0.25 \pm 0.00$ & $0.13 \pm 0.00$ & - \\
\hline & FICI $(\Sigma$ FIC $)$ & $0.53 \pm 0.00$ & $0.50 \pm 0.00$ & $0.37 \pm 0.00$ & - \\
\hline & Average of FICI (interpretation) & \multicolumn{4}{|c|}{0.4687 (synergy) } \\
\hline \multirow{4}{*}{ Salmonella typhi } & FIC GGldecoc & $0.13 \pm 0.00$ & $0.25 \pm 0.00$ & $0.25 \pm 0.00$ & - \\
\hline & $\mathrm{FIC} \mathrm{TClH}_{2} \mathrm{O}$ & $0.50 \pm 0.00$ & $0.13 \pm 0.00$ & $0.13 \pm 0.00$ & - \\
\hline & FICI ( $\Sigma$ FIC $)$ & $0.63 \pm 0.00$ & $0.38 \pm 0.00$ & $0.38 \pm 0.00$ & - \\
\hline & Average of FICI (interpretation) & \multicolumn{4}{|c|}{0.4583 (synergy) } \\
\hline
\end{tabular}

FIC $\mathrm{TClH}_{2} \mathrm{O}$ : fractional inhibitory concentration of aqueous extract of $T$. catappa leaves; FIC GGldecoc: fractional inhibitory concentration of decoction of G. glauca leaf.

Table 5 Phytochemical composition of the decoction of GGldecoc (G. glauca leaf) and aqueous extract of $\mathrm{TClH}_{2} \mathrm{O}(\mathrm{T}$. catappa leaf).

Secondary

metabolites Alkaloïds Flavonoïds Saponins Tanins Glucosides Phenols Steroïds Triterpens Anthocyanins Anthraquinones extracts

\begin{tabular}{llllllllllll}
$\mathrm{TeClH}_{2} \mathrm{O}$ & + & - & + & + & + & + & + & + & + & & - \\
$\mathrm{GnGldecoc}$ & - & + & + & + & + & + & + & + & - & + & + \\
\hline
\end{tabular}

“+”: present; “-”: absent; $\mathrm{TClH}_{2} \mathrm{O}$ : aqueous extract of $T$. catappa leaf; GGldecoc: decoction of G. glauca leaf. 
revealed the presence of phenols, tannins, saponins, triterpenes, and glycosides known to impact the growth and metabolism of microorganisms [40]. Though the detection of such metabolites does not automatically predict the antimicrobial activity of a plant extract, it has clearly been demonstrated that several compounds belonging to the investigated classes of metabolites showed antibacterial activities [40-42]. Tannins exert its antimicrobial activity by binding with proteins and adhesins, inhibiting enzymes, complexation with the cell wall and metal ions, or disruption of the plasmatic membrane [42]. Flavonoids have the ability to complex with proteins and bacterial cells forming irreversible complexes mainly with nucleophilic amino acids. This complex often leads to inactivation of the protein and loss of its function [43]. The mode of action of saponins against bacteria is due to its ability to cause leakage of proteins and certain enzymes from the cell [44]. The sensitivity of steroids and the membrane lipids indicate their specific association that causes leakage from liposomes. It seems that both active compounds from extracts directly or indirectly attach to the different site on bacterial cell. Mechanism of synergy is still insufficiently researched [45].

Synergy effects of the mixture of bioactive constituents contained in plant extracts are claimed to be responsible for the improved efficiency of many extracts. For a long time, the mechanisms underlying these synergy effects remained unexplained. With the exact knowledge of these mechanisms, it will be possible to develop a new generation of standardized, effect-optimized mono- and multi-extract preparations, which not only fulfill today's standards for quality, safety and efficacy of medicinal drugs but can ideally be used for the treatment of diseases that have been treated previously with chemosynthetics or antibiotics [46]. Synergy research in phytomedicine has established itself as a new key activity in recent years. It is one main aim of this research to find a scientific rational for the therapeutic superiority of many herbal drug extracts derived from traditional medicine as compared with single constituents thereof. For this reasons, the combinations of plant extracts could be a significant basis for the development of new approach to fight against resistance. Then the extracts contain mixtures of different bioactive compounds, which make microbial adaptability very difficult comparing to single-constituent antibiotics [47, 48].

\section{Conclusions}

The antibacterial activity exhibited by the crude extracts against Staphylococcus aureus, Pseudomonas aeruginosa, Salmonella typhi and Escherichia coli that are associated with various infectious diseases, has provided scientific justification in the use of these plants in Cameroonian folk medicine and could lead new phytomedicine. However, further isolation of active constituents from such plants, determination of their safety and pharmacokinetics properties are required.

\section{References}

[1] Fiamegos, Y. C., Kastritis, P. L., Exarchou, V., Han, H., Bonvin, A. M. J. J., Vervoort, J., Kim, L., et al. 2011. "Antimicrobial and Efflux Pump Inhibitory Activity of Caffeoylquinic Acids from Artemisia absinthium against Gram-Positive Pathogenic Bacteria." PLOS ONE 6: e18127.

[2] Akram, M., Shahid, M., and Khan, A. U. 2007. "Etiology and Antibiotics Resistance Pattern of Community Acquired Urinary Infections in JNMC Hospital Aligarh India." Annals of Clin. Microbiol. and Antimicrob. 6: 1-4.

[3] Mesaros, N., Nordmann, P., and Plésiat, P. 2007. "Pseudomonas aeruginosa: Resistance and Therapeutic Options at the Turn of the New Millennium." Clin. Microbiol. Infect. 13: 560-78.

[4] Tiago, G. F., Amanda, R. C. M., Karina, P. R., Adelisa, A. F., and Eulalia, A. X. 2012. "In Vitro Synergistic Effect of Psidium guineense (Swartz) in Combination with Antimicrobial Agents against Methicillin-Resistant Staphylococcus aureus Strains." The Science World Journal 2012: 158237.

[5] Nostro, A., Blanco, A. R., and Cannatelli, M. A. 2004. "Susceptibility of Methicillin-Resistant Staphylococci to Oregano Essential Oil, Carvacrol and Thymol." FEMS Microbiol. Lett. 230: 191-5.

[6] Cole, A. M., Tahk, S., Oren, A., Yoshioka, D., Kim, Y. H., 
Park, A., et al. 2001. "Determinants of Staphylococcus Aureus Nasal Carriage." Clin. Diagn. Lab Immunol. 8: 1064-9.

[7] Kluytmans, J., Van Belkum, A., and Verbrugh, H. 1997. "Nasal Carriage of Staphylococcus aureus, Epidemiology, Underlying Mechanisms, and Associated Risks." Clin. Microbiol. Rev. 10: 505-20.

[8] Todar, K. 2007. "Pathogenic E. coli." Online Textbook of Bacteriology, University of Wisconsin-Madison Department of Bacteriology Retrieved 2007: 11-30.

[9] Fine, M. J., Smith, M. A., Carson, C. A., Mutha, S. S., Sankey, S. S., Weissfeld, L. A., et al. 1996. "Prognosis and Outcomes of Patients with Community-Acquired Pneumonia: A Meta-analysis.” JAMA 275: 134-41.

[10] Adwan, G. M., Abu-Shanab, B. A., and Adwan, K. M. 2008. "In vitro Activity of Certain Drugs in Combination with Plant Extracts against Staphylococcus aureus Infections." Pakistan J. Med. Sci. 24: 541-4.

[11] Adjanohoun, J. E., Aboubakar, N., Dramane, K., Ebot, M. E., Ekpere, J. A., Enoworock, E. G., et al. 1996. Traditional Medicine and Pharmamacopoeia: Contribution to Ethnobotanical and Floristic Studies in Cameroon. Addis Ababa: Addis Ababa Organisation of African Unity, Scientific Technical and Research Comity.

[12] Chung, P. Y., Navaratnam, P., and Chung, L. Y. 2011. "Synergistic Antimicrobial Activity between Pentacyclic Triterpenoids and Antibiotics against Staphylococcus aureus Strains." Annals of Clin. Microbiol. and Antimicrob.10: 1-25.

[13] Hemaiswarya, S. A. K., and Kruthiventi, D. M. 2008. "Synergism between Natural Products and Antibiotics against Infectious Diseases." Phytomed. 15: 639-52.

[14] Franke, K., Porzel, A., and Schmidt, J. 2002. "Flavone-Coumarin Hybrids from Gnidia Socotrana." Phytochem. 61: 873-8.

[15] Nethravathi, H. R., Prashith, K. T. R., Vinayaka, K. S., Thippeswamy, N. B., Sudharshan, S. J., and Kumar, S. V. P. 2010. "Studies on Antioxidant and Anthelmintic Activity of Gnidia glauca (Fresen) Gilg." Asian J. of Biol. Sci. 5: 6-9.

[16] Ghosh, S., Ahire, M., Patil, S., Jabgunde, A., Dusane, M. B., Joshi, B. N., et al. 2012. Antidiabetic Activity of Gnidia glauca and Dioscorea bulbifera: Potent Amylase and Glucosidase Inhibitors. Cairo: Hindawi Publishing Corporation Evidence-Based Complemen and Alter Med.

[17] Swapnil, S. K., Deshbandhu, R. P., and Swapnil, D. M. 2011. "An Acute Oral Toxicity Study of Gnidia glauca (Fresen.) Gilg. in Albino Rats as Per OECD Guideline 425." Internat J. Pharmaceut. and Techn. Res. 3: 787-91.

[18] Wabo, H. K., Kowa, T. K., Lonfouo, A. H. N., Tchinda, A. T., Tane, P., Kikuchi, H., et al. 2012. "Phenolic Compounds and Terpenoids from Hypericum lanceolatum.” Rec. Nat. Prod. 6: 94-100.

[19] Zofou, D., Kowa, K. T., Wabo, H. K., Ngemenya, M. N., Tane, P., and Titanji, V. P. K. 2011. "Hypericum lanceolatum (Hypericaceae) as a Potential Source of New Anti-malarial Agents: A Bioassay-Guided Fractionation of the Stem Bark." Malaria Journal 10: 167.

[20] Boyom, F. F. 2004. "Essential Oils of Cameroonian Annonaceae: Chemical Analysis, Antioxydant and Antiplasmodial Activities." Ph.D. thesis, University of Yaoundé I.

[21] Focho, D. A., Egbe, E. A., Chuyong, G. B., Fongod, A. G. N., Fonge, B. A., Ndam, W. T., et al. 2010. "An Ethnobotanical Investigation of the Annonaceae on Mount Cameroon." J. Med. Plants Res. 4: 2148-58.

[22] Ezenwali, M. O., Njoku, O. U., and Okoli, C. O. 2010. Studies on the Anti-diarrheal Properties of Seed Extract of Monodora tenuifolia." Internat. J. Appl. Res. Nat. Prods. 2: 20-6.

[23] Njoku, U. O. 2007. "Antioxidant Activity of Seed Extract and Fractions of Monodora ténuifolia (Annonaceae)." doctorate thesis, University of Nigeria.

[24] Zeuko'o, M. E., Hzounda, F. J. B., Kenfack, T. I. F., Mejiato, C. P., Bakarnga-Via, I., Simo, K. M., et al. 2012. "Antifungal and Antioxidant Activities of Piptostigma calophyllum, Uvariodendron calophyllum and Uvariodendron molundense Growing in Cameroon." $J$. Biol. Act. Prod. Nat. 2: 110-8.

[25] Boyom, F. F., Fokou, P. V. T., Yamthe, L. R. T., Mfopa, A. N., Kemgne, E. M., Mbacham, W. F., et al. 2011. "Potent Antiplasmodial Extracts from Camerooian Annonaceae." J. Ethnopharmacol. 134: 717-24.

[26] Zheng, G. Q., Kenney, P. M., and Lam, L. K. 1992. "Sesquiterpenes from Clove (Eugeniacaryophyllata) as Potential Anticarcinogenic Agents." J. Nat. Prods. 55: 999-1003.

[27] Ayoola, G. A., Lawore, F. M., Adelowotan, T., Aibinu, I. E., Adenipekun, E., Coker, H. A. B., et al. 2008. "Chemical Analysis and Antimicrobial Activity of the Essential Oil of Syzigium aromaticum (Clove)." Afr. J. Microbiol. Res. 2: 162-6.

[28] Mi-Jin, P., Ki-Seob, G., Yang, I., Won-Sil, C., Hyun-Jin, J., Je-Won, C., et al. 2007. "Antifungal Activities of the Essential Oils in Syzygium aromaticum (L.) Merr. Et Perry and Leptospermum petersonii Bailey and Their Constituents against Various Dermatophytes." $J$. Microbiol. 45: 460-5.

[29] Fofana, S. 2004. "Biochemical Exploration of the Immunogenic Power of 3 Plants in Ivory Coast: Alstonia boonei (Apocynaceae), Mitragyna ciliata (Rubiaceae) and Terminalia catappa (Combretaceae)." Doctoral thesis, Université de Bamako.

[30] Zirihi, G. N., N'guessan, K., Kassy, N. J., Coulibaly, K., 


\section{Escherichia coli, Pseudomonas aeruginosa and Salmonella typhi}

and Djaman, A. J. 2012. "Evaluation and Comparison of Antifungal Activities of Terminalia catappa and Terminalia mantaly (Combretaceae) on the in vitro Growth of Aspergillus fumigates." J. Med. Plants Res. 6: 2299-308.

[31] Jagessar, R. C., and Alleyne, R. 2011. "Antimicrobial Potency of the Aqueous Extract of Leaves of Terminalia catappa." Acad. Res. Internat. 3: 2223-9553.

[32] Muhammad, A., and Mudi, S. Y. 2011. "Phytochemical Screening and Antimicrobial Activities of Terminalia catappa, Leaf Extracts.” Biokem 23: 35-9.

[33] Ackah, J., Bognan, A. A., Kra, A. K. M., Zirihi, G. N., and Guede-Guina, F. 2008. "Evaluation and Optimisation Assays of Anticandidosique Activities of Terminalia catappa Linn (Tekam 3), an Extract from Combretaceae of Ivory Coast Pharmacopia." Bulletin de la Société Royale des Sciences de Liège 77: 120-36.

[34] Caesar, L. N. 2007. "Study of the Phytochemistry and Biological Activities of Two Plants Used in Gabonnian Traditional Medicine: Terminalia catappa $L$. (Combretaceae), Kalanchoe crenata (andr.) and (Crassulaceae)." Doctoral thesis, Université de Bamako.

[35] Toghueo, K. R. M. 2012. "Potentialisation of Antifungal Activities of Extracts from Three Plants and Drug Commercial Drugs." Master thesis, University of Yaoundé I.

[36] Ngono, N. A., Biyiti, L. F., Amvam, Z. P. H., and Bouchet, P. H. 2000. "Evaluation of Antifungal Activity of Extracts of Two Cameroonian Rutaceae: Zanthoxylum leprieurii and Zanthoxylum xanthoxyloides." J. Ethnopharmacol. 70: 335-42.

[37] Odebeyi, O. O., and Sofowora, E. A. 1978. "Phytochemical Screening: Nigeria Medical Plants." $L$. Coydia 41: 234-325.

[38] Harbone, J. B. 1976. Phytochemical Methods: A Guide of Modern Techniques of Plants Analysis. London: Chapman and Hall.

[39] Greco, W. R., Bravo, G., and Parsons, J. C. 1995. "The Search for Synergy: A Critical Review from a Response Surface Perspective." Pharmacol. Rev. 47: 331-85.

[40] Cowan, M. M. 1999. "Plant Products as Antimicrobial Agents." Clin. Microbiol. Rev. 12: 564-82.

[41] Bruneton, J. 1999. "Pharmacognosie: Phytochimie, Plantes médicinales." Paris, Tec and Doc 3: 263-309.

[42] Kuete, V., and Efferth, T. 2010. "Cameroonian Medicinal Plants, Pharmacology and Derived Natural Products." Front Pharmacol. 1: 1-19.

[43] Ferreira, P. R. B., Mendes, C. S. O., Reis, S. B., Rodrigues, C. G., Alves De Oliveira, D., and Mercadante-Simões, M. O. 2011. "Morphoanatomy, Histochemistry and Phytochemistry of Psidium guineense Sw. (Myrtaceae) Leaves." J. Pharm. Res. 4: 942-4.

[44] Onwuliri, F. C., and Wonang, D. L. 2005. "Studies on the Combined Antibacterial Action of Ginger (Zingiber officinale $L$ ) and Garlic (Allium sativum L) on Some Bacteria." Nigerian J. Bot. 18: 224-8.

[45] Olgica, D., Stefanovi, D. D. S., and Ljiljana, R. 2012. "Synergistic Antibacterial Activity of Salvia officinalis and Cichorium intybus Extracts and Antibiotics." Acta Poloniae Pharmaceut-Drug Res. 69: 457-63.

[46] Wagner, H., and Ulrich-Merzenich, G. 2009. "Synergy Research: Approaching a New Generation of Phytopharmaceuticals." Phytomed. 16: 97-110.

[47] Matias, E. F., Santos, K. K., Almeida, T. S., Costa, J. G., and Coutinho, H. D. 2011. "Phytochemical Screening and Modulation of Antibiotic Activity by Ocimum $L$. gratissimum." Biomedicine \& Preventive Nutrition 1: 57-60.

[48] Shanmugam, H., Anil, K. K., and Mukesh, D. 2008. "Synergism between Natural Products and Antibiotics against Infectious Diseases." Phytomedicine 15: 639-52. 